\title{
Antimicrobial, antioxidant, cytotoxic and molecular docking properties of $\mathrm{N}$-benzyl-2,2,2-trifluoroacetamide
}

\author{
C. Balachandran · P. Saravana Kumar • Y. Arun • V. Duraipandiyan • \\ R. Lakshmi Sundaram • A. Vijayakumar - K. Balakrishna - S. Ignacimuthu • \\ N. A. Al-Dhabi $\cdot$ P. T. Perumal
}

Received: 23 February 2014/Accepted: 19 March 2014/Published online: 10 April 2014

(C) The Author(s) 2014. This article is published with open access at Springerlink.com

\begin{abstract}
N$-Benzyl-2,2,2-trifluoroacetamide was obtained by acylation of benzylamine with trifluoroacetic anhydride using Friedel-Crafts acylation method. The synthesised compound was confirmed by spectroscopic and crystallographic techniques. $\mathrm{N}$-Benzyl-2,2,2-trifluoroacetamide was assessed for its antimicrobial, antioxidant, cytotoxic and molecular docking properties. It showed good antifungal activity against tested fungi and moderate antibacterial activity. The minimum inhibitory concentration values of $\mathrm{N}$ benzyl-2,2,2-trifluoroacetamide against fungi were $15.62 \mu \mathrm{g} /$ $\mathrm{mL}$ against $A$. flavus, $31.25 \mu \mathrm{g} / \mathrm{mL}$ against $B$. Cinerea and $62.5 \mu \mathrm{g} / \mathrm{mL}$ against T. mentagrophytes, Scopulariopsis sp., C. albicans and $M$. pachydermatis. N-Benzyl-2,2,2-
\end{abstract}

C. Balachandran · P. S. Kumar · K. Balakrishna .

S. Ignacimuthu $(\square)$

Division of Microbiology and Cancer Biology, Entomology

Research Institute, Loyola College, Chennai 600 034, India

e-mail: entolc@hotmail.com

C. Balachandran

e-mail: balaeri09@gmail.com

Y. Arun · P. T. Perumal

Organic Chemistry Division, CSIR-Central Leather Research Institute, Chennai 600 020, India

V. Duraipandiyan $(\bowtie) \cdot$ N. A. Al-Dhabi

Department of Botany and Microbiology, Addriyah Chair for Environmental Studies, College of Science, King Saud University, P.O. Box 2455, Riyadh 11451, Saudi Arabia e-mail: entolc@hotmail.com

R. L. Sundaram

Central Research Facility, Sri Ramachandra University, Porur, Chennai 600116, India

A. Vijayakumar Department of Chemistry, Loyola College,

Chennai 600034, India trifluoroacetamide showed $78.97 \pm 2.24$ of antioxidant activity at $1,000 \mu \mathrm{g} / \mathrm{mL}$. Cupric ion reducing antioxidant capacity of $\mathrm{N}$-benzyl-2,2,2-trifluoroacetamide was dependent on the concentration. Ferric reducing antioxidant power assay of $N$-benzyl-2,2,2-trifluoroacetamide showed $(1.352 \pm 0.04 \mathrm{mM} \mathrm{Fe}(\mathrm{II}) / \mathrm{g})$ twofold higher value compared to the standard. $N$-Benzyl-2,2,2-trifluoroacetamide showed $75.3 \%$ cytotoxic activity at the dose of $200 \mu \mathrm{g} / \mathrm{mL}$ with $\mathrm{IC}_{50}$ (54.7\%) value of $100 \mu \mathrm{g} / \mathrm{mL}$. $N$-Benzyl-2,2,2-trifluoroacetamide was subjected to molecular docking studies for the inhibition AmpC beta-lactamase, Glucosamine-6-Phosphate Synthase and lanosterol 14 alpha-demethylase (CYP51) enzymes which are targets for antibacterial and antifungal drugs. Docking studies of $N$-benzyl-2,2,2-trifluoroacetamide showed low docking energy. $N$-Benzyl-2,2,2-trifluoroacetamide can be evaluated further for drug development.

Keywords Antimicrobial - Antioxidant - Cytotoxic . Molecular docking $\cdot N$-Benzyl-2,2,2-trifluoroacetamide

\section{Introduction}

The alarming rate at which antimicrobial resistance is growing poses great challenge. Drug resistance, especially by bacteria and fungi, is one of the major concerns to public health and scientific communities worldwide (Dismukes 2006; Goossens 2005). The development of fungal resistance to almost all classes of commercially available antifungal drugs (Kanafani and Perfect 2008) also poses enormous problems. Multi-drug resistance has been developing in fungi like Aspergillus, Saccharomyces cerevisiae, Candida, Cryptococcus (Bossche et al. 1998). The burden of antifungal resistance in high-risk patients is becoming a major concern. During the past two decades, 
the frequency of invasive and systemic fungal infections has increased dramatically due mainly to Candida species (Giraud et al. 2009). The growing number of immunocompromised patients as a result of cancer chemotherapy, organ transplantation, and HIV infection is also a challenge (Masubuchi et al. 2003). The interest in antifungal drug research has occurred because there is a critical need for new antifungal agents to treat life-threatening invasive fungal infections (Andriole 2000). Synthesised azole, amine and amide type of compounds showed good antifungal activities (Saha et al. 2012; Romagnoli et al. 2001). Azole compounds are divided into the older imidazoles and the new triazoles (De Pauw 2000). They inhibit fungal cytochrome P450 3A-dependent C14- $\alpha$-demethylase which is responsible for the conversion of lanosterol to ergosterol, thereby depleting ergosterol in the fungal cell membrane (Andriole 2000). Interaction of triazoles with cytochrome P450 may cause disturbances of hepatic enzymes (De Pauw 2000). Newer and less toxic antifungal agents are available for clinical use, but their clinical efficacy in some invasive fungal infections is not yet established (Andriole 1999), Allylamines (such as terbinafine or naftifine) are active mainly against dermatophytes and act by inhibiting the enzyme squalene epoxidase within the pathway of the biosynthesis of ergosterol, the main sterol of fungal membranes (Garibotto et al. 2011).There is an urgent need for new, more effective, less toxic and safe antimicrobial agents and the development of structurally new classes of antimicrobials with novel mechanisms of action as well as structural modifications to improve both their binding affinity and their spectrum of activity. The present study was carried out to assess the antimicrobial, antioxidant and cytotoxic properties of synthesized $N$-benzyl-2,2,2trifluoroacetamide.

\section{Materials and methods}

Preparation of $N$-benzyl-2,2,2-trifluoroacetamide

$5.5 \mathrm{~mL}$ of benzylamine was dissolved in $2 \mathrm{~mL}$ of dry ether taken in $100 \mathrm{~mL}$ quick fit conical flask. Then, $10 \mathrm{~mL}$ of Trifluoroacetic anhydride (TFAA) was added and the solution was allowed to stand; the precipitate was washed with aqueous $\mathrm{NaCHO}_{3}$ and water. It was filtered and dried in vacuum; the final yield was $3 \mathrm{~g}$ (Fig. 1). The synthesis of the compound has been reported using polymer-based $S$ benzyl triflurothioacetate (Svirskaya and Leznoff 1987).

\section{Bacterial strains}

The following Gram positive, negative bacteria, clinical isolates and fungi were used for the experiment. Gram-

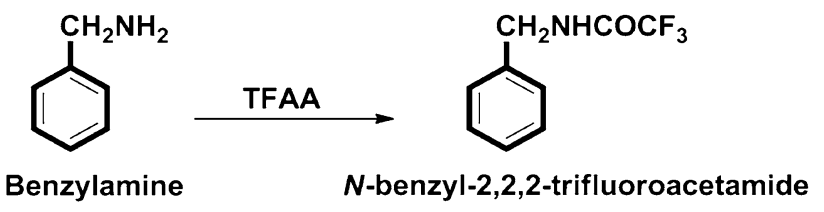

Fig. 1 Synthesis of $N$-benzyl-2,2,2-trifluoroacetamide

positive bacteria: Micrococcus luteus MTCC 106, Bacillus subtilis MTCC 441, Staphylococcus aureus MTCC 96 and Staphylococcus epidermidis MTCC 3615; Gram-negative bacteria: Shigella flexneri MTCC 1457, Enterobacter aerogenes MTCC 111, Salmonella paratyphi-B, Klebsiella pneumoniae MTCC 109, Pseudomonas aeruginosa MTCC 741, Proteus vulgaris MTCC 1771 and Salmonella typhimurium MTCC 1251. The reference cultures were obtained from the Institute of Microbial Technology (IMTECH), Chandigarh, 160 036, India. Clinical isolates; Escherichia coli (ESBL-3984, Extended Spectrum BetaLactamase), Escherichia coli (ESBL-3904), Klebsiella pneumoniae (ESBL-3971), Klebsiella pneumoniae (ESBL75799), Klebsiella pneumoniae (ESBL-3894), Klebsiella pneumoniae (ESBL-3967) and Staphylococcus aureus (MRSA-methicillin resistant). All cultures were obtained from the Department of Microbiology, Christian Medical College, Vellore, Tamil Nadu, India. Bacteria inoculums were prepared by growing cells in Mueller-Hinton Broth (Himedia) for $24 \mathrm{~h}$ at $37^{\circ} \mathrm{C}$. These cell suspensions were diluted with sterile MHB to provide initial cell counts of about $10^{-4} / \mathrm{mL} \mathrm{CFU/mL}$.

Fungal strains

Malassezia pachydermatis, Trichophyton mentagrophytes 66/01, Scopulariopsis sp. 101/01, Candida albicans, Trichophyton rubrum 57/01, Aspergillus flavus and Botrytis cinerea were obtained from the Department of Microbiology, Christian Medical College, Vellore, Tamil Nadu, India. The filamentous fungi were grown on Sabouraud Dextrose Agar (SDA) slants at $28{ }^{\circ} \mathrm{C}$ for 10 days and the spores were collected using sterile doubled-distilled water and homogenized. Yeast was grown on Sabouraud Dextrose Broth (SDB) at $28{ }^{\circ} \mathrm{C}$ for $48 \mathrm{~h}$.

Antimicrobial activity

Antibacterial and antifungal activities were carried out using disc diffusion method (Balachandran et al. 2013). Petri plates were prepared with $20 \mathrm{~mL}$ of sterile MuellerHinton agar (MHA) (Hi-media, Mumbai). The test cultures were swabbed on the top of the solidified media and allowed to dry for 10 min and a specific amount $(25 \mu \mathrm{L}$ from the $20 \mathrm{mg} / \mathrm{mL}$ ) of the compound was added to each 
Table 1 Crystal data and structure tenement parameters of $N$-benzyl2,2,2-trifluoroacetamide

\begin{tabular}{|c|c|}
\hline Empirical formula & $\mathrm{C}_{9} \mathrm{H}_{8} \mathrm{~F}_{3} \mathrm{~N} \mathrm{O}$ \\
\hline Formula weight & 203.16 \\
\hline Temperature & 293(2) K \\
\hline Wavelength & $0.71073 \AA$ \\
\hline $\begin{array}{l}\text { Crystal system, space } \\
\text { group }\end{array}$ & Triclinic, $\mathrm{P}-1$ \\
\hline Unit cell dimensions & $\begin{array}{l}a=9.8131(6) \AA \text { alpha }=100.683(4)^{\circ} \\
b=10.0193(6) \AA \text { beta }=107.471(4)^{\circ} \\
c=11.4336(7) \AA \\
\quad \text { gamma }=109.820(4)^{\circ}\end{array}$ \\
\hline Volume & $955.73(10) \mathrm{A}^{3}$ \\
\hline$Z$, calculated density & $4,1.412 \mathrm{Mg} / \mathrm{m}^{3}$ \\
\hline Absorption coefficient & $0.132 \mathrm{~mm}^{-1}$ \\
\hline $\mathrm{F}(000)$ & 416 \\
\hline Crystal size & $0.30 \times 0.25 \times 0.20 \mathrm{~mm}$ \\
\hline $\begin{array}{l}\text { Theta range for data } \\
\text { collection }\end{array}$ & $1.97-26.62^{\circ}$ \\
\hline Limiting indices & $\begin{array}{l}-12 \leq h \leq 12,-12 \leq k \leq 12 \\
-13 \leq l \leq 14\end{array}$ \\
\hline $\begin{array}{l}\text { Reflections collected/ } \\
\text { unique }\end{array}$ & $14,056 / 3,994[R(\mathrm{int})=0.0282]$ \\
\hline $\begin{array}{l}\text { Completeness to } \\
\text { theta }=26.62\end{array}$ & $99.2 \%$ \\
\hline Max. and min. transmission & 0.9741 and 0.9615 \\
\hline Refinement method & Full-matrix least-squares on $F^{2}$ \\
\hline Data/restraints/parameters & $3,994 / 0 / 253$ \\
\hline Goodness-of-fit on $\mathrm{F}^{2}$ & 1.575 \\
\hline $\begin{array}{l}\text { Final R indices } \\
{[I>2 \operatorname{sigma}(\mathrm{I})]}\end{array}$ & $\mathrm{R} 1=0.1078, \mathrm{wR} 2=0.3916$ \\
\hline$R$ indices (all data) & $\mathrm{R} 1=0.1675, \mathrm{wR} 2=0.4571$ \\
\hline Largest diff. peak and hole & 0.732 and $-0.404 \mathrm{e} \mathrm{A}^{-3}$ \\
\hline
\end{tabular}

disc. The loaded discs were placed on the surface of the medium and left for $30 \mathrm{~min}$ at room temperature for compound diffusion. Negative control was prepared using respective solvents. The plates were incubated for $24 \mathrm{~h}$ at $37^{\circ} \mathrm{C}$ for bacteria and for $48 \mathrm{~h}$ at $28{ }^{\circ} \mathrm{C}$ for fungi. Zones of inhibition were recorded in millimetres and the experiment was repeated twice.

Minimum inhibitory concentration (MIC)

Minimum inhibitory concentration studies of the isolated compound were performed according to the standard reference method for bacteria (Balachandran et al. 2013), for filamentous fungi (CLSI 2008) and yeasts (NCCLS/ CLSI 2002).The concentrations $(1,000,500,250,125$, $62.5,31.25$ and $15.62 \mu \mathrm{g} / \mathrm{mL}$ ) of the compound were dissolved in DMSO (2\%) and used. They were added to each medium in 96-well plates. An inoculum of $100 \mu \mathrm{L}$ from each well was inoculated. The antifungal agent Fluconazole for fungi and antibacterial agent Streptomycin for bacteria were included in the assays as positive controls. For fungi, the plates were incubated for $48-72 \mathrm{~h}$ at $28{ }^{\circ} \mathrm{C}$ and for bacteria the plates were incubated for $24 \mathrm{~h}$ at $37^{\circ} \mathrm{C}$. The MIC for fungi was defined as the lowest extract concentration, showing no visible fungal growth after incubation time. $5 \mu \mathrm{L}$ of tested broth was placed on the sterile MHA plates for bacteria and incubated at respective temperature. The MIC for bacteria was determined as the lowest concentration of the compound inhibiting the visual growth of the test cultures on the agar plate.

\section{Antioxidant activity}

Antioxidant activity of $N$-benzyl-2,2,2-trifluoroacetamide was investigated by DPPH radical scavenging assay, cupric ion reducing antioxidant capacity (CUPRAC) assay, ferric reducing antioxidant power (FRAP) assay and total antioxidant capacity (TAC).

\section{DPPH radical scavenging assay}

DPPH (2,2-diphenyl-1-picryl hydrazyl) radical scavenging activity of $\mathrm{N}$-benzyl-2,2,2-trifluoroacetamide was determined based on the method described (Wang and $\mathrm{Li}$ 2011). $40 \mu \mathrm{L}$ of various concentrations $(125-1,000 \mu \mathrm{g} /$ $\mathrm{mL)}$ of $N$-benzyl-2,2,2-trifluoroacetamide was added to ethanolic solution of DPPH $(0.1 \mathrm{M}, 2,960 \mu \mathrm{L})$. The absorbance of reaction mixture was measured at $517 \mathrm{~nm}$ after 30 min of incubation in the dark at room temperature. AA (ascorbic acid) was used as the standard control. The free radical scavenging activity was calculated as follows:

DPPH scavenging activity $=\left[\left(A_{\mathrm{C}}-A_{\mathrm{S}} / A_{\mathrm{C}}\right) \times 100\right]$

where $A_{\mathrm{C}}$ is the absorbance of the control and $A_{\mathrm{S}}$ is the absorbance of the extract/standard (AA).

Cupric ion reducing antioxidant capacity assay

The cupric ion reducing capacity was measured according to the method (Balachandran et al. 2013). The standard antioxidant $\mathrm{AA}$ and $\mathrm{N}$-benzyl-2,2,2-trifluoroacetamide were mixed with $\mathrm{CuCl}_{2}(1 \mathrm{~mL}, 10 \mathrm{mM})$, neocuproine $(1 \mathrm{~mL}, 7.5 \mathrm{mM})$ and ammonium acetate buffer $(\mathrm{pH} 7.0$, $1 \mathrm{~mL}, 1 \mathrm{M}$ ), adjusted to total volume of $4 \mathrm{~mL}$. After 30-min incubation at room temperature, the absorbance was measured at $450 \mathrm{~nm}$ against blank. In the assay, $\mathrm{Cu}$ (II) was reduced to $\mathrm{Cu}$ (I) through the action of electron donating antioxidant. 
Ferric reducing antioxidant power assay

The assay was performed according to the methods of $\mathrm{Ku}-$ bola and Siriamornpun (2011) and Duganath et al. (2010). FRAP reagent $(50 \mathrm{~mL}$ of $300 \mathrm{mM}$ acetate buffer (pH 3.6), $5 \mathrm{~mL}$ of $10 \mathrm{mM}$ TPTZ (2,4,6-tripyridyl-s-triazine) in $40 \mathrm{mM} \mathrm{HCl}$ and $5 \mathrm{~mL} 20 \mathrm{mM} \mathrm{FeCl} \cdot 6 \mathrm{H}_{2} \mathrm{O}$ ) was prepared. FRAP reagent $(2,960 \mu \mathrm{L})$ was mixed with $40 \mu \mathrm{L}$ of $N$-benzyl-2,2,2-trifluoroacetamide. AA was used as standard as in the other methods. The mixtures were incubated at $37{ }^{\circ} \mathrm{C}$ for $4 \mathrm{~min}$ and the absorbance was measured at $593 \mathrm{~nm}$. Results were expressed as $\mathrm{Fe}^{2+}$ equivalents per gram dry mass.

Total antioxidant capacity

The total antioxidant capacity of the compound was evaluated using the phosphomolybdenum method (Prieto et al. 1999). $N$-Benzyl-2,2,2-trifluoroacetamide (1 mg/mL) was dissolved in a mixture of $2.9 \mathrm{~mL}$ of reagent solution (0.6 M sulfuric acid, $28 \mathrm{mM}$ sodium phosphate and $4 \mathrm{mM}$ ammonium molybdate) and incubated at $95{ }^{\circ} \mathrm{C}$ for $90 \mathrm{~min}$. After the samples were cooled to ambient temperature, the absorbance of the solution was measured at $695 \mathrm{~nm}$ against blank. The results were reported as $\mathrm{mg}$ Gallic acid equivalents/g of $\mathrm{N}$-benzyl-2,2,2-trifluoroacetamide.

Cytotoxic properties

A549 lung adenocarcinoma cancer cell line was obtained from National Institute of Cell Sciences, Pune. A549 cell line was maintained in complete tissue culture medium Dulbecco's Modified Eagle's Medium with $10 \%$ Fetal Bovine Serum and $2 \mathrm{mM}$ L-Glutamine, along with antibiotics (about 100 International Unit/mL of penicillin, $100 \mu \mathrm{g} / \mathrm{mL}$ of streptomycin) with the $\mathrm{pH}$ adjusted to 7.2. The cytotoxicity was determined according to the method of Balachandran et al. (2012) with some changes. Cells $(5,000$ cells/well) were seeded in 96 -well plates containing medium with different concentrations such as 1,000, 800, 600, 400, 200 and $100 \mu \mathrm{g} / \mathrm{mL}$. The cells were cultivated at $37{ }^{\circ} \mathrm{C}$ with $5 \% \mathrm{CO}_{2}$ and $95 \%$ air in $100 \%$ relative humidity. After cultivation, the medium was removed. An aliquot of $100 \mu \mathrm{L}$ of medium containing $1 \mathrm{mg} / \mathrm{mL}$ of 3-(4,5-dimethylthiazol-2-yl)-2,5-diphenyl-tetrazolium bromide was loaded in the plate. The cells were cultured for $4 \mathrm{~h}$ and then the solution in the medium was removed. An aliquot of $100 \mu \mathrm{L}$ of DMSO was added to the plate, which was shaken until the crystals were dissolved. The cytotoxicity against cancer cells was determined by measuring the absorbance of the converted dye at $540 \mathrm{~nm}$ in an Enzyme linked immune sorbent assay reader. Cytotoxicity of each sample was expressed as the half maximal

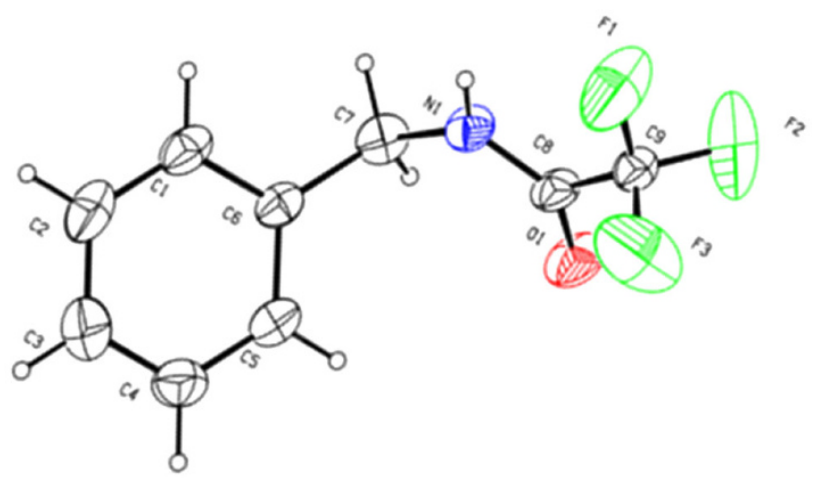

Fig. 2 ORTEP diagram of $N$-benzyl-2,2,2-trifluoroacetamide

Table 2 Antimicrobial activity of $N$-benzyl-2,2,2-trifluoroacetamide $(1 \mathrm{mg} / \mathrm{mL})$ using disc diffusion method against bacteria and fungi

\begin{tabular}{|c|c|c|}
\hline Organism & Compound & Streptomycin \\
\hline \multicolumn{3}{|l|}{ Gram-positive bacteria } \\
\hline Bacillus subtilis & 15 & 22 \\
\hline Micrococcus luteus & 14 & 24 \\
\hline Staphylococcus aureus & - & 14 \\
\hline Staphylococcus epidermidis & - & 14 \\
\hline \multicolumn{3}{|l|}{ Gram-negative bacteria } \\
\hline Shigella flexneri & - & 24 \\
\hline Enterobacter aerogenes & - & 22 \\
\hline Salmonella paratyphi-B & - & 18 \\
\hline Klebsiella pneumoniae & 11 & 20 \\
\hline Pseudomonas aeruginosa & - & 30 \\
\hline Proteus vulgaris & 17 & 30 \\
\hline Salmonella typhimurium & 13 & 24 \\
\hline \multicolumn{3}{|l|}{ Clinical isolates } \\
\hline Staphylococcus aureus (MRSA) & 15 & 20 \\
\hline Klebsiella pneumoniae (ESBL-3894) & - & 12 \\
\hline Klebsiella pneumoniae (ESBL-75799) & - & 22 \\
\hline Klebsiella pneumoniae (ESBL-3967) & - & 14 \\
\hline Klebsiella pneumoniae (ESBL-3971) & 15 & 15 \\
\hline Escherichia coli (ESBL-3904) & 10 & 14 \\
\hline Escherichia coli (ESBL-3984) & - & 12 \\
\hline Fungi & & Ketoconazole \\
\hline Trichophyton mentagrophytes & 15 & 20 \\
\hline Trichophyton rubrum & - & 20 \\
\hline Scopulariopsis sp. & 16 & 24 \\
\hline Aspergillus flavus & 26 & 29 \\
\hline Botrytis cinerea & 17 & 22 \\
\hline Malassezia pachydermatis & 15 & 26 \\
\hline Candida albicans & 17 & 28 \\
\hline
\end{tabular}

Values represent the mean of three replications; Streptomycin Standard antibacterial agent, Ketoconazole standard antifungal agent, Negative control DMSO (nil)

'-' no activity 
Table 3 Antimicrobial activity of $N$-benzyl-2,2,2-trifluoroacetamide using minimum inhibitory concentration against bacteria and fungi

\begin{tabular}{lll}
\hline Organism & Compound & Streptomycin \\
\hline Gram-positive Bacteria & & \\
Bacillus subtilis & 125 & 25 \\
Micrococcus luteus & 125 & 6.25 \\
Gram-negative bacteria & & \\
Klebsiella pneumonia & 500 & 25 \\
Proteus vulgaris & 62.5 & 6.25 \\
Salmonella typhimurium & 125 & 25 \\
Clinical isolates & & \\
Staphylococcus aureus (MRSA) & 62.5 & 6.25 \\
Klebsiella pneumoniae (ESBL-3971) & 62.5 & 6.25 \\
Escherichia coli (ESBL-3904) & 500 & 25 \\
Fungi & & Ketoconazole \\
Trichophyton mentagrophytes & 62.5 & $<12.5$ \\
Trichophyton rubrum & - & $<12.5$ \\
Scopulariopsis sp. & 62.5 & $<12.5$ \\
Aspergillus flavus & 15.62 & $<12.5$ \\
Botrytis cinerea & 31.25 & 6.25 \\
Malassezia pachydermatis & 62.5 & 25 \\
Candida albicans & 62.5 & 6.25 \\
\hline Valeprent & &
\end{tabular}

Values represent the mean of three replications; Streptomycin standard antibacterial agent, Ketoconazole standard antifungal agent, Negative control DMSO (nil)

'-' no activity

inhibitory concentration $\left(\mathrm{IC}_{50}\right)$ value. The $\mathrm{IC}_{50}$ value is the concentration of test sample that causes $50 \%$ inhibition of cell growth, averaged from three replicate experiments.

Molecular docking studies

The docking analysis was developed by AutoDock Tools (ADT) (Sanner 1999) version 1.5.6 and Autodock version 4.2.5.1 programs; (Autodock, Autogrid, Copyright1989-2012) from the Scripps Research Institute, http:// www.scripps.edu/mb/olson/doc/autodock.

\section{Ligand preparation}

Ligand $N$-benzyl-2,2,2-trifluoroacetamide was crystallized and single-crystal XRD structure was obtained (Table 1). Then, the structure was saved as Protein Data Bank file format for input to ADT using Mercury 3.1. In ADT, ligand bond torsion was assigned and saved in PDBQT file format for input into docking.

\section{Protein preparation}

Three-dimensional structures of AmpC beta-lactamase (PDB: 1KE4), Glucosamine-6-Phosphate Synthase (PDB:
Table 4 Antioxidant activity of $N$-benzyl-2,2,2-trifluoroacetamide using DPPH and CUPRAC assays

\begin{tabular}{llllll}
\hline $\begin{array}{l}\text { Con } \mu \mathrm{g} / \\
\mathrm{mL}\end{array}$ & DPPH & \multicolumn{3}{l}{ CUPRAC } \\
\cline { 2 - 3 } \cline { 5 - 6 } & Compound & AA & & Compound & AA \\
\hline 100 & $17.16 \pm 3.12$ & $90.18 \pm 0.51$ & & $0.658 \pm 0.02$ & $1.656 \pm 0.02$ \\
200 & $25.30 \pm 0.38$ & $91.58 \pm 0.76$ & $0.871 \pm 0.01$ & $1.725 \pm 0.02$ \\
400 & $52.36 \pm 1.27$ & $92.83 \pm 0.51$ & & $1.007 \pm 0.01$ & $1.857 \pm 0.01$ \\
500 & $69.71 \pm 2.09$ & $93.69 \pm 0.82$ & & $1.179 \pm 0.01$ & $1.863 \pm 0.02$ \\
1000 & $78.97 \pm 2.24$ & $95.05 \pm 0.19$ & & $1.663 \pm 0.01$ & $2.073 \pm 0.02$ \\
\hline
\end{tabular}

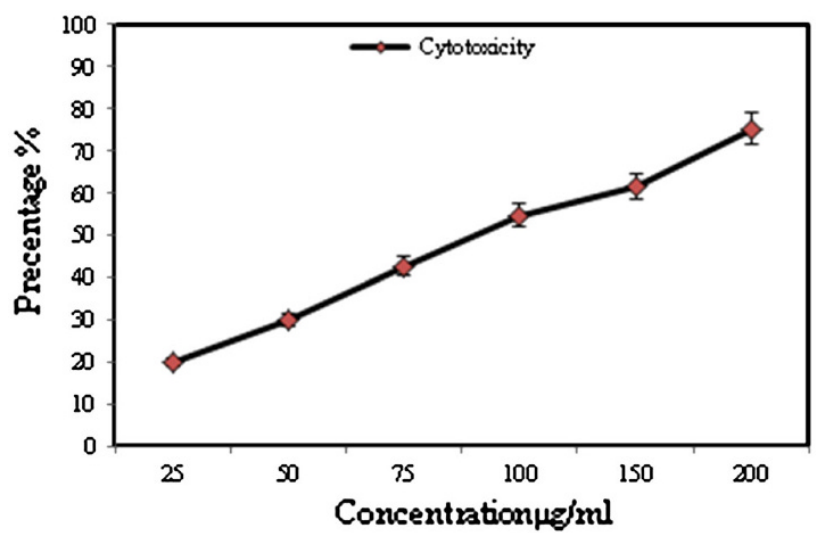

Fig. 3 MTT Assay showing the cytotoxicity of $N$-benzyl-2,2,2trifluoroacetamide against A549 lung adenocarcinoma cancer cell line

2VF5) and lanosterol 14 alpha-demethylase (CYP51) (PDB: 3JUV) were retrieved from the Protein Data Bank (PDB) http://www.pdb.org. For the protein structure, polar hydrogen atoms were added, lower occupancy residue structures were deleted, and incomplete side chains were replaced using the ADT. Further ADT was used to remove crystal water, added Gagteiger charges to each atom and merged the non-polar hydrogen atoms to the protein structure. The distance between donor and acceptor atoms that form a hydrogen bond was defined as $1.9 \AA$ with a tolerance of $0.5 \AA$ and the acceptor-hydrogen-donor angle was not less than $120^{\circ}$. The structures were then saved in PDBQT file format for input into docking.

Docking analysis

For docking calculations of ligand with AmpC beta-lactamase, a grid box size of $126 \times 66 \times 72 \AA^{3}$ points (spacing between the grid points of $0.675 \AA$ ) was used which centred on the mass centre $(52.108,-0.936,22.921)$ of the crystallographic macromolecule encompassing all active site atoms. For docking calculations of ligand with Glucosamine-6-Phosphate Synthase, a grid box size of $126 \times 114 \times 94 \AA^{3}$ points (spacing between the grid points of $0.375 \AA$ ) was used which centred on the mass 

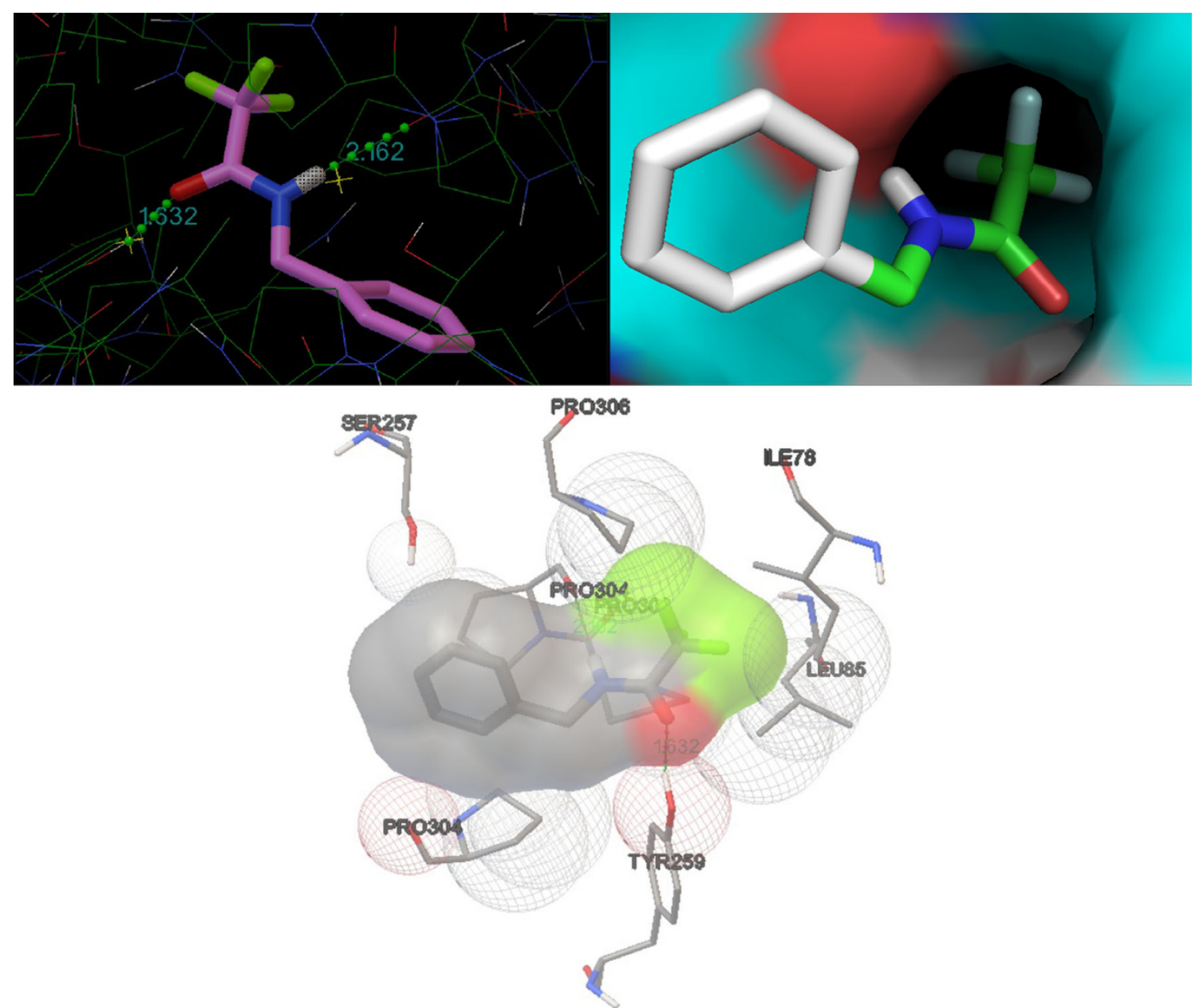

Fig. 4 Putative binding pose of compound $N$-benzyl-2,2,2-trifluoroacetamide with AmpC beta-lactamase (PDB entry code1KE4). Docking of compound $\mathrm{N}$-benzyl-2,2,2-trifluoroacetamide with AmpC beta-lactamase where hydrogen bonding interactions are shown in dotted lines

centre $(22.985,25.198,7.976)$ of the crystallographic macromolecule encompassing all active site atoms. For docking calculations of ligand with lanosterol 14 alphademethylase, a grid box size of $110 \times 110 \times 110 \AA^{3}$ points (spacing between the grid points of $0.375 \AA$ ) was used which centred on the mass centre $(-82.426,25.738$, -6.232) of the crystallographic macromolecule encompassing all active site atoms. Then, grid energy calculations were carried out using ADT.

$\mathrm{N}$-Benzyl-2,2,2-trifluoroacetamide was docked to target protein complexes 1KE4, 2VF5 and 3JUV with the protein molecule considered as a rigid body and the ligand being flexible. The search was carried out with the Lamarckian genetic algorithm (Morris et al. 1998); populations of 150 individuals with a mutation rate of 0.02 were evolved for 10 generations. Evaluation of the results was done by sorting the different complexes with respect to the predicted binding energy. A cluster analysis based on root mean square deviation values, with reference to the starting geometry, was subsequently performed and the lowest energy conformation of the more populated cluster was considered as the most trustable solution. The outputs were exported to ADT and Pymol (The PyMOL Molecular Graphics System 2010) for visual inspection of the binding modes and interactions of the compounds with amino acid residues in the active sites.

Statistical analysis

Antimicrobial, cytotoxic and antioxidant activities of $\mathrm{N}$ benzyl-2,2,2-trifluoroacetamide were statistically analyzed by Duncan multiple range test at $P=0.05$ with the help of SPSS 11.5 version software package.

\section{Results and discussion}

$\mathrm{N}$-Benzyl-2,2,2-trifluoroacetamide was obtained by acylation of benzylamine with TFAA using Friedel-Crafts acylation method. $\mathrm{Mp} 76{ }^{\circ} \mathrm{C}$ (melting point), lit $\mathrm{mp}$ 

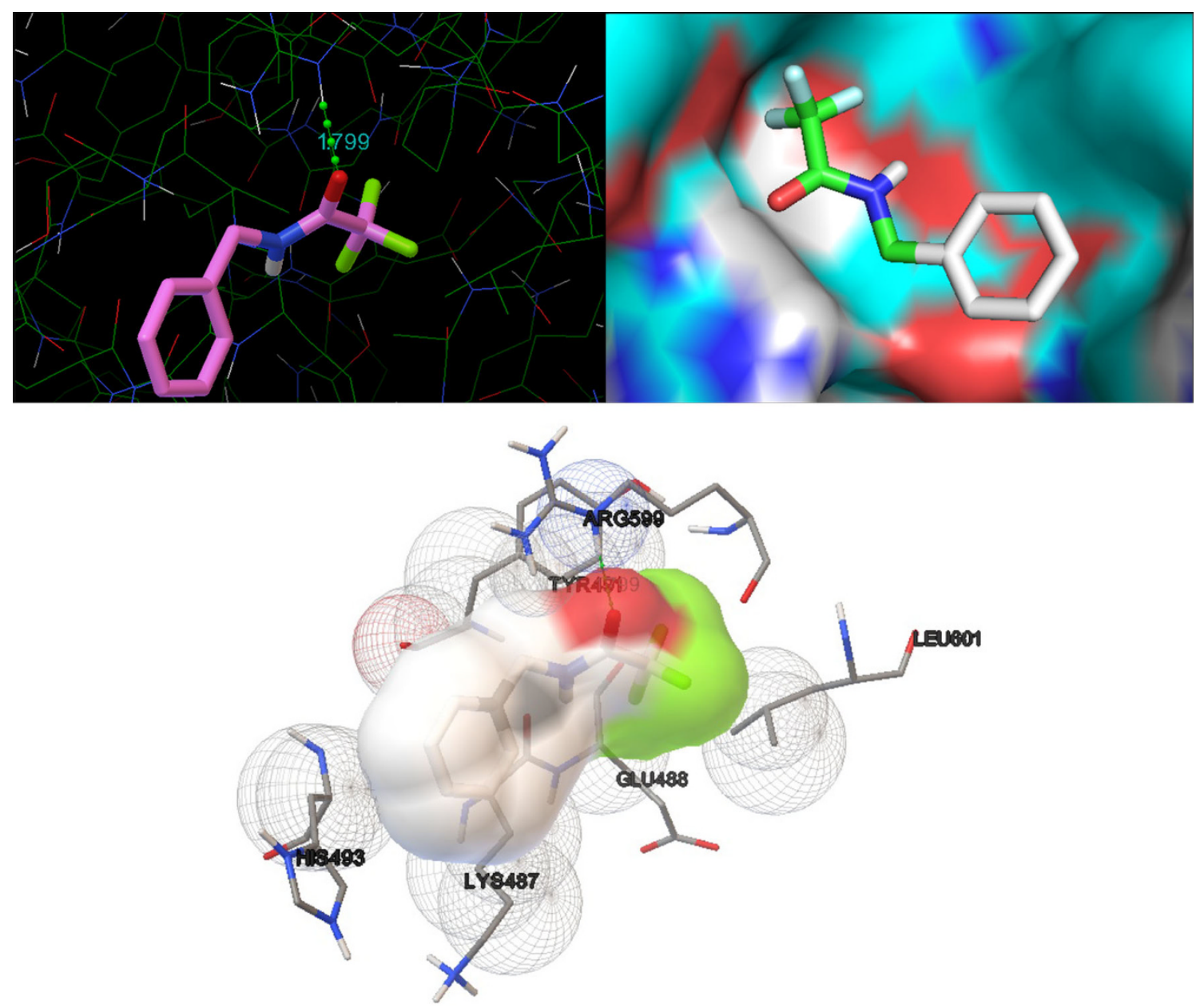

Fig. 5 Putative binding pose of compound $N$-benzyl-2,2,2-trifluoroacetamide with Glucosamine-6-Phosphate Synthase (PDB entry code 2 VF5). Docking of compound $N$-benzyl-2,2,2-trifluoroacetamide with

75-76 ${ }^{\circ} \mathrm{C}$, IR: $v_{\max } \mathrm{KBr} \mathrm{cm}^{-1}: 3,306,3,109(\mathrm{NH}), 3,036$, 2,961, 1,703 (COCF3), 1,562, 1,497, 1,455, 1,442, 1,367, $1,181,1,080,1,026,996,970,917,820,713 .{ }^{1} \mathrm{H}$ NMR $(\delta$, $\left.\mathrm{CDCL}_{3}, 400 \mathrm{MHz}\right): 7.37(1 \mathrm{H}, \mathrm{m}, \mathrm{H}-4), 7.30(2 \mathrm{H}, \mathrm{d}$, $J=6.8 \mathrm{~Hz}, \mathrm{H}-2$ and $\mathrm{H}-6), 7.38(2 \mathrm{H}, \mathrm{d}, J=6.8 \mathrm{~Hz}, \mathrm{H}-3$ and $\mathrm{H}-5), 7.04(1 \mathrm{H}$, brs, $-\mathrm{NH}) .{ }^{13} \mathrm{C}$ NMR $\left(\delta, \mathrm{CDCL}_{3}\right.$, $100 \mathrm{MHz}$ ): 135.92 (C-1), 127.93 (C-2, C-6), 128.99 (C-3, C-5), 28.24 (C-4), 43.85 (-CH2), 157.13 (CO), 117.34 (CF3). In our earlier communication, we have isolated 2-acetyl benzylamine from Adhatoda vasica leaves and investigated its antimycobacterial activity (Ignacimuthu and Shanmugam 2010). This resulted in the formation of $\mathrm{N}$-benzyl-2,2,2-trifluoroacetamide as expected (Table 1; Fig. 2). The identification of the compound was confirmed by IR, ${ }^{1} \mathrm{H}$ NMR, ${ }^{13} \mathrm{C}$ NMR and crystallography data as well as comparison with the data reported in the literature (Svirskaya and Leznoff 1987). In this communication, we report the antimicrobial, antioxidant, cytotoxicity and molecular docking properties of this compound.
Glucosamine-6-Phosphate Synthase where hydrogen bonding interactions are shown in dotted lines

$\mathrm{N}$-Benzyl-2,2,2-trifluoroacetamide was assessed for antimicrobial activity of bacteria and fungi. The compound showed moderate activity against Gram positive and negative bacteria; however, the compound showed prominent activity against tested fungi. The compound showed activity against bacteria, such as $B$. subtilis, M. luteus, $P$. vulgaris, S. aureus (MRSA) and K. pneumoniae (ESBL3971) at the concentration of $1 \mathrm{mg} / \mathrm{mL}$. The compound showed prominent activity against fungi; such as T. mentagrophytes, Scopulariopsis sp., A. flavus, B. cinerea and $M$. pachydermatis. MIC values were: $62.5 \mu \mathrm{g} / \mathrm{mL}$ against $P$. vulgaris, S. aureus (MRSA) and K. pneumoniae (ESBL3971) (Table 2). MIC values for tested fungi were: $15.62 \mu \mathrm{g} / \mathrm{mL}$ against $A$. flavus, $31.25 \mu \mathrm{g} / \mathrm{mL}$ against $B$. cinerea, $62.5 \mu \mathrm{g} / \mathrm{mL}$ against T. mentagrophytes, Scopulariopsis sp., C. albicans and M. pachydermatis (Table 3).

The radical scavenging activity of $N$-benzyl-2,2,2-trifluoroacetamide at different concentrations is shown in Table 4. $N$-Benzyl-2,2,2-trifluoroacetamide showed $78.97 \pm 2.24$ 


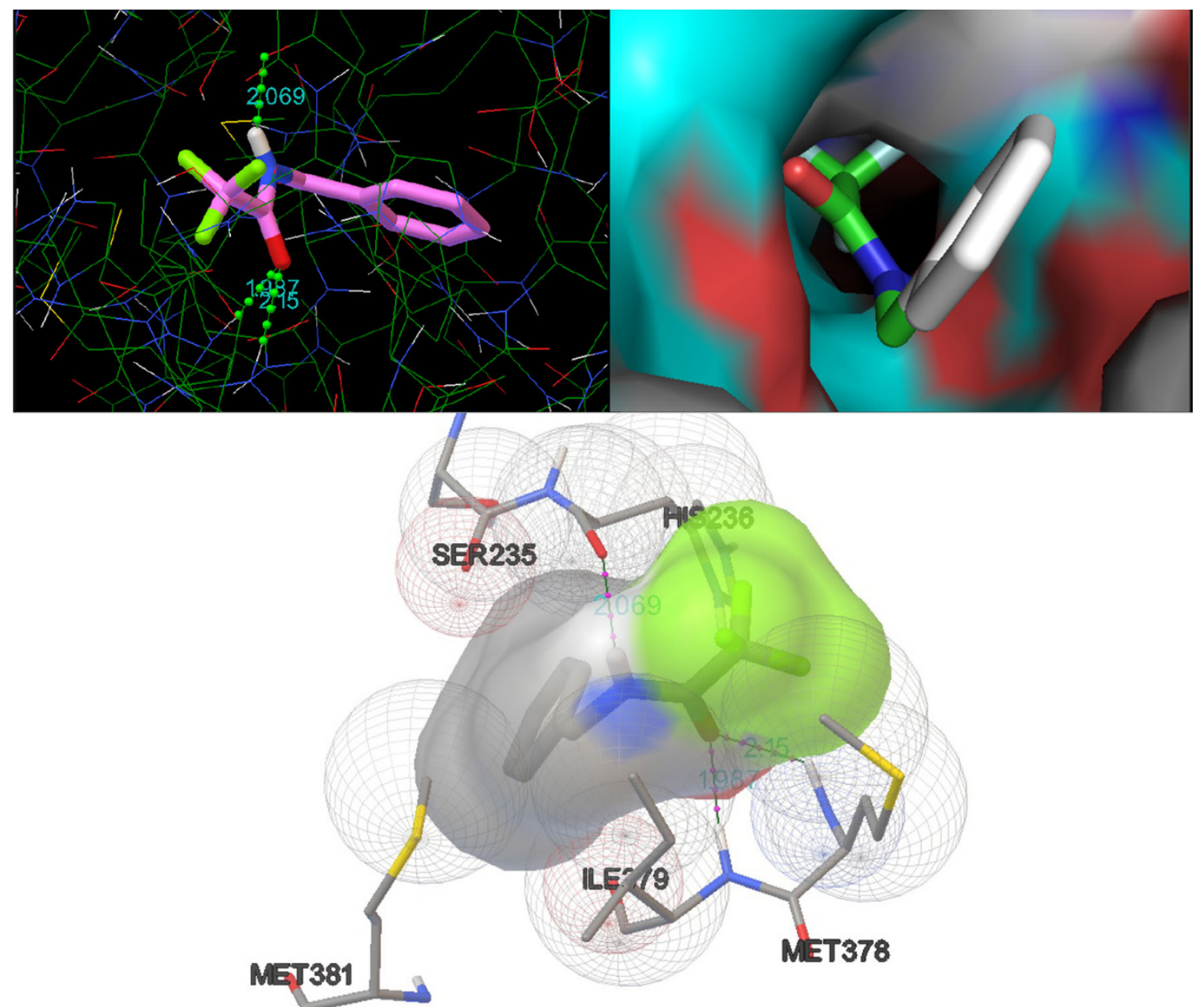

Fig. 6 Putative binding pose of compound $N$-benzyl-2,2,2-trifluoroacetamide with lanosterol 14 alpha-demethylase (CYP51) (PDB entry code $3 J U V)$. Docking of compound $N$-benzyl-2,2,2-trifluoroacetamide

activity at $1,000 \mu \mathrm{g} / \mathrm{mL}$, while standard AA showed $95.05 \pm 0.19$ activity. CUPRAC of $N$-benzyl-2,2,2-trifluoroacetamide also showed concentration-dependant activity. It was slightly lower than standard AA as shown in Table 4. The ferric reducing antioxidant power (FRAP) assay measures the reduction of ferric iron $\left(\mathrm{Fe}^{3+}\right)$ to ferrous iron $\left(\mathrm{Fe}^{2+}\right)$ in the presence of antioxidants. This assay is also commonly used for the routine analysis of single antioxidants and total antioxidant activity of plant extracts (Halvorsen et al. 2002; Schlesier et al. 2002). The results showed activity comparable to the standard AA at $40 \mu \mathrm{L}$ (Table 3). $N$-Benzyl-2,2,2-trifluoroacetamide $(1.352 \pm 0.04 \mathrm{mM} \mathrm{Fe}(\mathrm{II}) / \mathrm{g})$ showed approximately twofold higher ferric reducing capacity compared to the standard reference AA ( $2.354 \pm 0.13 \mathrm{mM} \mathrm{Fe}(\mathrm{II}) / \mathrm{g})$. The total antioxidant capacity of $N$-benzyl-2,2,2-trifluoroacetamide was determined by the phosphomolybdenum method. This method is based on the reduction of molybdenum Mo (VI) to Mo (V) by the antioxidant compounds and the formation of a green $\mathrm{Mo}(\mathrm{V})$-antioxidant complex with maximum absorption with lanosterol 14 alpha-demethylase (CYP51) where hydrogen bonding interactions are shown in dotted lines

at $695 \mathrm{~nm}$. The high absorbance values indicated that the sample possessed significant antioxidant activity of $N$-benzyl2,2,2-trifluoroacetamide $0.024 \pm 0.03 \mathrm{mg} \mathrm{GAE} / \mathrm{g}$ and AA $0.037 \pm 0.03 \mathrm{mg} \mathrm{GAE} / \mathrm{g}$.

$\mathrm{N}$-Benzyl-2,2,2-trifluoroacetamide showed cytotoxic activity in vitro against A549 lung adenocarcinoma cancer cell line. It showed $75.3 \%$ activity at the dose of $200 \mu \mathrm{g} /$ $\mathrm{mL}$ with $\mathrm{IC}_{50}(54.7 \%$ ) value of $100 \mu \mathrm{g} / \mathrm{mL}$ (Fig. 3). All the concentrations used in the experiment decreased the cell viability significantly $(P<0.05)$ in a concentrationdependent manner. Pyridyl and thiazolyl bisamide compounds showed good anticancer activity (Scott et al. 2008). Several cinnamic acid-derived bisamides have been reported from the above genus. Aglaia, Odorinol exhibited antileukemic activity in the P-388 system (Hayashi et al. 1982).

The docking simulations in the active sites of $\mathrm{AmpC}$ beta-lactamase (PDB: 1KE4), Glucosamine-6-Phosphate Synthase (PDB: 2VF5) and lanosterol 14 alpha- 
demethylase (CYP51) (PDB: 3JUV) were performed by the AutoDock Tools (ADT) version 1.5.6 and Autodock version 4.2.5.1 programs. The target protein structures were docked with $N$-benzyl-2,2,2-trifluoroacetamide which provided least values of the binding energy. The binding profile of the $N$-benzyl-2,2,2-trifluoroacetamide docking with AmpC beta-lactamase showed interaction with ILE78, LEU85, TYR250, SER257, PRO304 \& PRO306 amino acids and formed two hydrogen bonds with TYR250 \& PRO304 amino acids which resulted in the lowest free binding energy of $-5.53 \mathrm{kcal} / \mathrm{mol}$ (Fig. 4). Best docked orientation of $N$-benzyl-2,2,2-trifluoroacetamide with Glucosamine-6-Phosphate Synthase showed interactions with LYS487, GLU488, TYR491, HIS493, ARG599 and LEU601 and formed a hydrogen bond with TYR491 amino acid which resulted in the lowest free binding energy of $-4.37 \mathrm{kcal} / \mathrm{mol}$ (Fig. 5). Best docked orientation of $N$ benzyl-2,2,2-trifluoroacetamide with lanosterol 14 alphademethylase (CYP51) showed interactions with SER235, HIS236, MET378, ILE379 and MET381 amino acids and formed three hydrogen bonds with HIS236, MET378 and ILE379 amino acids which resulted in the lowest free binding energy of $-5.95 \mathrm{kcal} / \mathrm{mol}$ (Fig. 6). Chai et al. (2011) reported the molecular docking of novel azole series of 1-(1H-1,2,4-triazol-1-yl)-2-(2,4-difluoro-phenyl)-3-[(4substitutedphenyl)-piperazin-1-yl]-propan-2-olsag against CYP51 with antifungal activity. Guan et al. (2010) reported the synthesis and molecular docking of 28 novel triazole derivatives against CYP51. The molecular docking analysis and pharmacophoric analysis of antifungal azole against cytochrome 51 from Mycobacterium tuberculosis were also reported (Tripathi et al. 2009).

\section{Conclusion}

The compound $N$-benzyl-2,2,2-trifluoroacetamide showed good antifungal activity against tested fungi and moderate antibacterial activity. Antioxidant activity was concentration dependant. $N$-Benzyl-2,2,2-trifluoroacetamide showed $75.3 \%$ cytotoxic activity at the dose of $200 \mu \mathrm{g} / \mathrm{mL}$ with $\mathrm{IC}_{50}(54.7 \%)$ value of $100 \mu \mathrm{g} / \mathrm{mL}$. $N$-Benzyl-2,2,2-trifluoroacetamide was subjected to molecular docking studies for the inhibition of AmpC beta-lactamase, Glucosamine6-Phosphate Synthase and lanosterol 14 alpha-demethylase (CYP51) enzymes which are targets for antimicrobials. Docking studies of $N$-benzyl-2,2,2-trifluoroacetamide showed low docking energy. $N$-Benzyl-2,2,2-trifluoroacetamide can be evaluated further for drug development.

Acknowledgments We would like to thank the Visiting Professor Program, Deanship of Scientific Research at King Saud University, Riyadh. We also thank Dr. A.P.T. Augustine and Dr. B.S. Mary Vithiya for their help.
Open Access This article is distributed under the terms of the Creative Commons Attribution License which permits any use, distribution, and reproduction in any medium, provided the original author(s) and the source are credited.

\section{References}

Andriole VT (1999) Current and future antifungal therapy: new targets for antifungal agents. J Antimicrob Chemoth 44:151-162

Andriole VT (2000) Current and future antifungal therapy: new targets for antifungal therapy. Int $\mathrm{J}$ Antimicrob Agents $16: 317-321$

Balachandran C, Duraipandiyan V, Ignacimuthu S (2012) Cytotoxic (A549) and antimicrobial effects of Methylobacterium sp. isolate (ERI-135) from Nilgiris forest soil, India. Asian Pac. J Trop Biomed 2(9):712-716

Balachandran C, Duraipandiyan V, Balakrishna K, Lakshmi Sundaram R, Vijayakumar A, Ignacimuthu S, Al-Dhabi NA (2013) Synthesis and medicinal properties of plant-derived vilangin. Environ Chem Lett 11:303-308

Bossche HV, Dromer F, Improvisi L, Chiu ML, Rex JH, Sanglard D (1998) Antifungal drug resistance in pathogenic fungi. Med Mycol 36:119-128

Chai X, Zhang J, Cao Y, Zou Y, Wu Q, Zhang D, Jiang Y, Sun Q (2011) New azoles with antifungal activity: design, synthesis, and molecular docking. Bioorgan Med Chem Lett 21:686-689

Clinical and Laboratory Standards Institute (CLSI) Reference method for Broth dilution antifungal susceptibility testing of filamentous fungi; Approved standard second-Edition CLSI document M38-A2 (ISBN 1-56238-668-9) (2008) Clinical and Laboratory Standards Institute, 940, West valley Road, Suite 1400, Wayne, Pennsylvania 19087-1898 USA

De Pauw BE (2000) New antifungal agents and preparations. Int J Antimicrob Agents 16:147-150

Dismukes WE (2006) Antifungal therapy: lessons learned over the past 27 years. Clin Infect Dis 42:1289-1296

Duganath N, Reddy KN, Nagasowjanya J, Sridhar S, Jayaveera KN (2010) Evaluation of phytochemical and in vitro antioxidant activity of Filicium decipiens. Ann Biol Res 1:134-140

Garibotto FM, Sortino MA, Kouznetsov VV, Enriz RD, Zacchinoa SA (2011) Synthesis and antifungal activity of $\mathrm{N}$-aryl- $\mathrm{N}$ benzylamines and of heir homoallyl analogues. Regional Issue "Organic Chemistry in Argentina". ARKIVOC 149-161

Giraud F, Guillon R, Logé C, Pagniez F, Picot C, Borgne ML et al (2009) Synthesis and structure-activity relationships of 2-phenyl1-[(pyridinyl- and piperidinylmethyl) amino]-3-(1H-1,2,4-triazol-1-yl) propan-2-ols as antifungal agents. Bioorgan Med Chem Lett 19:301-304

Goossens H (2005) European status of resistance in nosocomial infections. Chemotherapy 51:177-181

Guan Z, Chai X, Yu S, Hu H, Jiang Y, Meng Q, Wu Q (2010) Synthesis, molecular docking, and biological evaluation of novel triazole derivatives as antifungal agents. Chem Biol Drug Des 76:496-504

Halvorsen BL, Holte K, Myhrstad MCW, Barikmo I, Hvattum E, Remberg SF et al (2002) A systematic screening of total antioxidants in dietary plants. J Nutr 132(3):461-471

Hayashi N, Lee K, Hall IH, McPhail AT, Huang H (1982) Structure and stereochemistry of (-)-odorinol, an antileukemic diamide from Aglaia odorata. Phytochemistry 21:2371-2373

Ignacimuthu S, Shanmugam N (2010) Antimycobacterial activity of two natural alkaloids, vasicine acetate and 2-acetyl benzylamine, isolated from Indian shrub Adhatoda vasica Ness, leaves. J Biol Sci 35:565-570

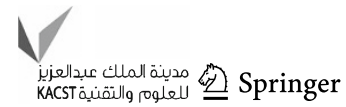


Kanafani ZA, Perfect JR (2008) Resistance to antifungal agents: mechanisms and clinical impact. Clin Infect Dis 46:120-128

Kubola J, Siriamornpun S (2011) Phytochemicals and antioxidant activity of different fruit fractions (Peel, pulp, aril and seed) of Thai gac (Momordica cochinchinensis Spreng). Food Chem 127(3):1138-1145

Masubuchi M, Ebiike H, Kawasaki KI, Sogabe S, Morikami K, Shiratori Y et al (2003) Synthesis and biological activities of benzofuran antifungal agents targeting fungal $N$-myristoyltransferase. Bioorgan Med Chem 11:4463-4478

Morris GM, Goodsell DS, Halliday RS, Huey R, Hart WE, Belew RK, Olson AJ (1998) Automated docking using a Lamarckian genetic algorithm and an empirical binding free energy function. J Comput Chem 19:1639-1662

NCCLS, M27-A2 (2002) In National Committee for Clinical Laboratory Standards. Reference method for broth dilution antifungal susceptibility testing of yeasts: proposed Standard

Prieto P, Pineda M, Aguilar M (1999) Spectrophotometric quantitation of antioxidant capacity through the formation of a phosphor molybdenum complex: specific application to the determination of vitamin E. Anal Biochem 269:337-341

Romagnoli C, Mares D, Bruni A, Andreotti E, Manfrini M, Vicentini CB (2001) Antifungal activity of 5 new synthetic compounds vs. Trichophyton rubrum and Epidermophyton floccosum. Mycopathologia 153:129-132
Saha S, Priyadharshini A, Dhanasekaran D, Thajuddin N, Chandraleka S, Chandramohan G, Panneerselvam A (2012) Preclinical evaluation and molecular docking of 4-phenyl-1-Napthylphenyl acetamide (4P1NPA)from Streptomyces sp. DPTB16 as a potent antifungal compound. Comput Biol Med 42:542-547

Sanner MF (1999) Python: a programming language for software integration and development. J Mol Graph Model 17:57-61

Schlesier K, Harwat M, Böhm V, Bitsch R (2002) Assessment of antioxidant activity by using different in vitro methods. Free Radical Res 36(2):177-178

Scott DA, Aquila BM, Bebernitz GA, Cook DJ, Dakin LA, Deegan TL, Hattersley MM, Ioannidis S, Lyne PD, Omer CA, Ye M, Zheng X (2008) Pyridyl and thiazolyl bisamide CSF-1R inhibitors for the treatment of cancer. Bioorgan Med Chem Lett 18(17):4794-4797

Svirskaya PI, Leznoff CC (1987) Trifluoroacetylation of amines and amino acids by polymer-bound trifluoroacetylation reagents. J Org Chem 52:1362-1364

The PyMOL Molecular Graphics System (2010), Version 1.3, Schrödinger, LLC

Tripathi SK, Singh S, Singh SK (2009) Pharmacophoric analysis and molecular docking studies on antifungal Azoles as CYP51 inhibitors. Biobytes 4:37-41

Wang X, Li X (2011) Evaluation of antioxidant activity of isoferulic acid in vitro. Nat Prod Commun 6:1285-1288 